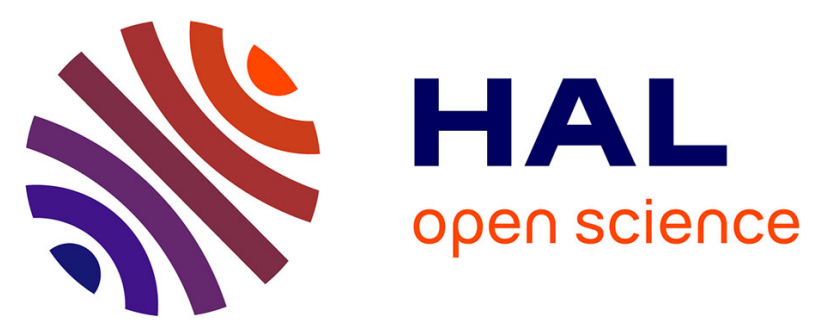

\title{
Characterization of a ring-hydroxylating dioxygenase from phenanthrene-degrading Sphingomonas sp. strain LH128 able to oxidize benz[a]anthracene.
}

Luc Schuler, Yves Jouanneau, Sinéad M Ní Chadhain, Christine Meyer, Maria Pouli, Gerben J Zylstra, Pascal Hols, Spiros N Agathos

\section{To cite this version:}

Luc Schuler, Yves Jouanneau, Sinéad M Ní Chadhain, Christine Meyer, Maria Pouli, et al.. Characterization of a ring-hydroxylating dioxygenase from phenanthrene-degrading Sphingomonas sp. strain LH128 able to oxidize benz[a]anthracene.. Applied Microbiology and Biotechnology, 2009, 83 (3), pp.465-75. 10.1007/s00253-009-1858-2 . hal-01063081

\section{HAL Id: hal-01063081 \\ https://hal.science/hal-01063081}

Submitted on 11 Sep 2014

HAL is a multi-disciplinary open access archive for the deposit and dissemination of scientific research documents, whether they are published or not. The documents may come from teaching and research institutions in France or abroad, or from public or private research centers.
L'archive ouverte pluridisciplinaire HAL, est destinée au dépôt et à la diffusion de documents scientifiques de niveau recherche, publiés ou non, émanant des établissements d'enseignement et de recherche français ou étrangers, des laboratoires publics ou privés. 


\section{䌼 Springer}

Manuscript for review

\section{Characterization of a ring-hydroxylating dioxygenase from phenanthrene-degrading Sphingomonas sp. strain LH128 able to oxidize benz[a]anthracene}

\begin{tabular}{|r|l|}
\hline Journal: & Applied Microbiology and Biotechnology \\
\hline Manuscript ID: & draft \\
\hline Manuscript Category: & Original Paper \\
\hline Author: & n/a \\
\hline Complete List of Authors: & $\begin{array}{l}\text { Schuler, Luc; Université Catholique de Louvain, Unit of } \\
\text { Bioengineering } \\
\text { Jouanneau, Yves; CEA-Grenoble, Laboratoire de Chimie et Biologie } \\
\text { des Métaux, iRTSV, CEA, CNRS, Université J. Fourier UMR 5249, } \\
\text { Ní Chadhain, Sinéad; Rutgers University, Biotechnology Center for } \\
\text { Agriculture and the Environment } \\
\text { Meyer, Christine; CEA-Grenoble, Laboratoire de Chimie et Biologie } \\
\text { des Métaux, iRTSV, CEA, CNRS, Université J. Fourier UMR 5249, } \\
\text { Pouli, Maria; Université Catholique de Louvain, Unit of } \\
\text { Bioengineering } \\
\text { Zylstra, Gerben; Rutgers University, Biotechnology Center for } \\
\text { Agriculture and the Environment } \\
\text { Hols, Pascal; Université Catholique de Louvain, Institut des } \\
\text { Sciences de la Vie, Unité de Génétique } \\
\text { Agathos, Spiros; Universite Catholique de Louvain, Unit of } \\
\text { Bioengineering }\end{array}$ \\
\hline Keyword: & $\begin{array}{l}\text { polycyclic aromatic hydrocarbons, dioxygenase, ring hydroxylation, } \\
\text { substrate specificity, overexpression, catabolic genes }\end{array}$ \\
\hline \hline
\end{tabular}

\section{(5) ScholaroNE"


1 Characterization of a ring-hydroxylating dioxygenase from phenanthrene-degrading

2 Sphingomonas sp. strain LH128 able to oxidize benz $[a]$ anthracene.

3

4 Luc Schuler ${ }^{1}$, Yves Jouanneau ${ }^{2}$, Sinéad M. Ní Chadhain ${ }^{3}$, Christine Meyer $^{2}$, Maria Pouli ${ }^{1}$, 5 Gerben J. Zylstra ${ }^{3}$, Pascal Hols ${ }^{4}$ and Spiros N. Agathos ${ }^{1 *}$

$6{ }^{1}$ Unité de Génie Biologique, Institut des Sciences de la Vie, Université catholique de 7 Louvain, Place Croix du Sud, 2/19, B-1348 Louvain-la-Neuve, Belgium.

$8{ }^{2}$ Laboratoire de Chimie et Biologie des Métaux, iRTSV, CEA, CNRS, Université J. Fourier 9 UMR 5249, CEA-Grenoble, F-38054 Grenoble Cedex 9, France.

103 Biotechnology Center for Agriculture and the Environment, Cook College, Rutgers 11 University, New Brunswick, New Jersey, USA.

$12{ }^{4}$ Unité de Génétique, Institut des Sciences de la Vie, Université catholique de Louvain, Place 13 Croix du Sud 5, B-1348 Louvain-la-Neuve, Belgium.

14 Running Title: Dioxygenase from Sphingomonas sp. strain LH128

15 Keywords: Bioremediation, meta-cleavage operon genes, indigo formation, Rieske non-heme 16 iron oxygenase

$17 *$ Corresponding author. Unité de Génie Biologique,

Institut des Sciences de la Vie,

Université catholique de Louvain,

Place Croix du Sud, 2/19,

B-1348 Louvain-la-Neuve, Belgium.

Phone: +32 10473644 .

Fax: 3210473062.

E-mail: spiros.agathos@uclouvain.be. 


\section{ABSTRACT}

26 Sphingomonas sp. strain LH128 was isolated from a polycyclic aromatic hydrocarbon (PAH)

27 contaminated soil using phenanthrene as the sole source of carbon and energy. A dioxygenase

28 complex, phnAlfA2f encoding the $\alpha$ and $\beta$ subunit of a terminal dioxygenase responsible for

29 the initial attack on PAHs, was identified and isolated from this strain. PhnA1f showed 98\%,

$3078 \%$ and $78 \%$ identity to the $\alpha$ subunit of Novosphingobium aromaticivorans strain F199,

31 Sphingomonas sp. strain CHY-1 and Sphingobium yanoikuyae strain B1 respectively. When

32 overexpressed in E. coli, PhnA1fA2f was able to oxidize low molecular weight PAHs,

33 chlorinated biphenyls, dibenzo-p-dioxin and the high molecular weight PAHs

34 benz $[a]$ anthracene, chrysene and pyrene. The action of PhnA1fA2f on benz $[a]$ anthracene 35 produced two benz $[a]$ anthracene dihydrodiols. 


\section{INTRODUCTION}

Polycyclic aromatic hydrocarbons are found ubiquitously in nature (natural oil seeps, bushfires, volcanoes etc.) but anthropogenic activities have led to an increased incidence of these recalcitrant pollutants due to, amongst others, the burning, handling or disposal of organic matter including coal tars, crude oil and petroleum products. For the purpose of bioremediation, microorganisms able to use these pollutants as the sole source of carbon and energy are extensively studied (Cerniglia 1992; Johnsen et al. 2005). Amongst these, sphingomonads have received much attention due to their ability to degrade a wide range of aromatic hydrocarbons. Sphingomonas species able to degrade mono- and polycyclic aromatic hydrocarbons (Pinyakong et al. 2000; Schuler et al. 2008; Story et al. 2001), phenols (Cai and Xun 2002), carbofuran (Feng et al. 1997; Kim et al. 2004), estradiol (Fujii et al. 2003), dibenzofurans (Bunz and Cook 1993; Fortnagel et al. 1990), biphenyls (Happe et al. 1993; Kim and Zylstra 1999; Peng et al 2002; Zylstra and Kim 1997), dibenzo-p-dioxin (Bunz and Cook 1993; Hong et al. 2002) and herbicides (Johannesen et al. 2003; Sorensen et al. 2001) have been isolated. In the last few years, attention has been turned towards identifying and characterizing the genes involved in PAH degradation, allowing a closer look at pathways potentially useful in bioremediation (Pinyakong et al. 2003a).

PAH degradation by aerobic bacteria is generally initiated by the introduction of both atoms of $\mathrm{O}_{2}$ to the aromatic ring of the substrate (Butler and Mason 1997; Wackett 2002). This initial reaction, which is catalysed by aromatic ring hydroxylating dioxygenases, involves the dihydroxylation of the carbon-carbon double bond of adjacent carbon atoms. The enzymes responsible for the initial attack on PAHs from Sphingomonas sp. strain CHY-1, which was isolated for its ability to degrade chrysene (Demaneche et al. 2004; Jounneau et al. 2006) and Sphingobium yanoikuyae strain B1, which was isolated for its ability to degrade biphenyl (Ni Chadhain et al. 2007), are known and their respective crystal structures were determined (Jakoncic et al. 2007a; 2007b, Yu et al. 2007). In a recent study we have successfully 
62 identified the genes governing the angular attack on fluorene by the gram-negative 63 Sphingomonas sp. strain LB126 which uses fluorene as the sole source of carbon and energy 64 (Schuler et al. 2008).

65 Although the complete sequence of plasmid pNL1 which harbours a catabolic gene cluster of $40 \mathrm{~kb}$ as well as the putative initial dioxygenase of Novosphingobium aromaticivorans F199 67 has been sequenced, the activity of the initial dioxygenase has not yet been investigated 68 (Romine et al. 1999). Sphingomonads harbour multiple copies of genes predicted to encode 69 the terminal component of Rieske-type oxygenases (Pinyakong et al. 2000; Romine et al. 70 1999). They constitute a large family of two- or three-component metalloenzymes whose 71 catalytic activity component is generally a heteromeric $\alpha 3 \beta 3$ hexamer containing one Rieske72 type $[2 \mathrm{Fe}-2 \mathrm{~S}]$ cluster and one nonheme iron atom per $\alpha$ subunit. The fact that all 73 phenanthrene-degrading sphingomonads carry a similar pathway organization as found in 74 Sphingomonas sp. strain CHY-1, Sphingobium yanoikuyae strain B1, Novosphingobium 75 aromaticivorans strain F199 and Sphingobium sp. strain P2, indicates that this organization 76 has been conserved for a long time and is quite stable despite the apparent complex 77 organization compared to the more 'logical' organization of PAH-degradation genes in 78 members of the genus Pseudomonas. These data could help to explain that Sphingomonas 79 spp. started as phenanthrene degraders and their respective initial dioxygenases became 80 substrate-relaxed in order to oxidize a large variety of PAHs.

81 Sphingomonas sp. strain LH128 was isolated from a heavily polluted soil (Bastiaens et 82 al. 2000) and is capable of growing on phenanthrene as the sole source of carbon and energy. 83 Strain LH128 is also able to transform indole to indigo in the presence of phenanthrene (data 84 not shown). No indigo formation was observed when the strain was grown in the presence of 85 glucose suggesting that the dioxygenase oxidizing indole must be induced by phenanthrene. 86 Moreover strain LH128 is able to degrade anthracene, dibenzothiophene, fluorene (Bastiaens 87 et al. 2000) and the N-heterocyclic PAHs acridine, phenanthridine, benzo[f]quinoline and 
88 benzo[ $h]$ quinoline (van Herwijnen et al. 2004). In this study the multicomponent ring 89 hydroxylating dioxygenase from Sphingomonas sp. strain LH128 was cloned and its function 90 towards a variety of substrates was investigated. This newly characterized dioxygenase is 91 shown to be closely related to BphA1fA2f from Novosphingobium aromaticivorans strain 92 F199 (98\% identities) but to display significant differences in catalytic behaviour as reflected 93 by a broad substrate range notably including the capacity to oxidize benz[a]anthracene.

\section{MATERIALS AND METHODS}

96 Reagents. PAHs and antibiotics were obtained from Sigma-Aldrich (St. Louis, MO). Primers 97 were purchased from Sigma-Genosys. Silicone oil (Rhodorsil 47V20) was purchased from 98 VWR International (France). Restriction enzymes were from New England Biolabs (Ipswich, 99 MA).

100

101 Bacterial strains, plasmids, and media.

102 Sphingomonas sp. strain LH128 was kindly provided by VITO (Vlaamse Instelling voor 103 Technologisch Onderzoek, Belgium). Escherichia coli Top10 (Invitrogen, Carlsbad, CA) was 104 used as the recipient strain in all cloning experiments. E. coli BL21(DE3) was used for gene 105 expression analysis. PCR amplicons were either cloned into pDrive (Qiagen, Valencia, CA) 106 while pET30f (Novagen, San Diego, CA) and pVLT31 (de Lorenzo et al. 1993) were used as 107 expression vector. MM284 minimal medium (Mergeay et al. 1985) was used for growing 108 Sphingomonas sp. strain LH128 and was supplemented with phosphate buffer (50 mM; $109 \mathrm{KH}_{2} \mathrm{PO}_{4}, \mathrm{~K}_{2} \mathrm{HPO}_{4}, \mathrm{pH}$ 7.2) instead of Tris buffer. Phenanthrene was provided as crystals in 110 both solid and liquid media. LB broth (Sambrook et al. 1990) was used as complete medium 111 for growing E. coli strains. Solid media contained 2\% agar. When needed, ampicillin, 112 streptomycin, tetracycline or kanamycin was added to the medium at 100, 200, 10 and 20 $113 \mu \mathrm{g} / \mathrm{ml}$, respectively. Sphingomonas sp. strain LH128 was grown at $30^{\circ} \mathrm{C}$, and E. coli strains 
114 were grown at $37^{\circ} \mathrm{C}$. Bacterial growth was determined by optical density readings at $600 \mathrm{~nm}$

$115\left(\mathrm{OD}_{600}\right)$.

116

117 DNA manipulations and molecular techniques. Total DNA from pure cultures of

118 Sphingomonas sp. strain LH128 was extracted using the Ultra Clean DNA Isolation Kit

119 (MoBio, Carlsbad, CA) following the manufacturer's recommendations or using standard

120 methods (Sambrook et al. 1990) when a higher DNA concentration was needed. Plasmid

121 DNA extractions, restriction enzyme digestions, ligations, transformations, sequencing and

122 agarose gel electrophoresis were carried out using standard methods (Sambrook et al. 1990).

123

124 Polymerase chain reaction (PCR) and primer design. PCR primers RHDA1f-F (5'125 CACCGCGGCAACCAGAT -3') and RHDA2f-R (5'- ACCATGGTATAGGTCCA-3') were 126 constructed based upon conserved nucleic acid alignments of the initial dioxygenase from 127 Sphingomonas yanoikuyae strain B1 (EF152282) Novosphingobium aromaticivorans strain 128 F199 (AF079317) and Sphingomonas sp. strain CHY-1 (AJ633551) using Clustal X software 129 (Thompson et al. 1997). All PCR reactions were carried out using PCR Master Mix (Abgene, 130 Surrey, UK) and were performed in a programmable T-Gradient Thermocycler (Biometra, 131 Göttingen, Germany). PCR products were purified and cloned into either the pDrive or 132 pGEMT-easy plasmids.

134 Construction of plasmids for protein overexpression. Construction of the plasmids used in 135 this study involved multiple PCR amplifications and cloning steps. The phnAlfA2f fragment 136 (2048 bp) was amplified by PCR with the primers pairs: 5' - CATATGAATGGATCGTCGG 137 3' and 5'-AAGCTTGATCGAATTTGCTTATGCG -3', introducing NdeI and HindIII sites 138 (italics) at the ends of the amplicon. The PCR amplicon was cloned into pDrive, sequenced, 139 then subcloned into the NdeI and HindIII site of expression vector pET30f (Novagen, San 
140 Diego, CA). The phnAlfA2f pair of genes was also transferred into pVLT31 (de Lorenzo et al. 141 1993) as a XbaI - HindIII fragment from pET30fphnAlfA2f. These constructs were 142 transformed into E. coli BL21(DE3) for expression analysis.

144 Sodium dodecyl sulphate-polyacrylamide gel electrophoresis (SDS-PAGE). Bacterial 145 cells were pelleted by centrifugation and washed with $10 \mathrm{ml}$ ice-cold phosphate buffer (140 $146 \mathrm{mM} \mathrm{NaCl}, 10 \mathrm{mM} \mathrm{Na}_{2} \mathrm{HPO}_{4}, 2.7 \mathrm{mM} \mathrm{KCl}, 1.8 \mathrm{mM} \mathrm{NaH}_{2} \mathrm{PO}_{4}, \mathrm{pH}$ 7.4). $1 \mathrm{ml}$ of ice-cold 147 phosphate buffer was added to the pellet and $550 \mu$ of the suspension was subjected to 148 sonication on ice for $20 \mathrm{~s}$ (5 s pulse interval; $40 \%$ of maximum amplitude). After 149 centrifugation the supernatant and the pellet were mixed with an equal volume of loading 150 solution. SDS-PAGE was performed on $13.3 \%$ polyacrylamide mini gels. After 151 electrophoresis, protein staining was performed with Coomassie brilliant blue R-250.

152

153 Dioxygenase overexpression and in vivo assays. Strains BL21(DE3)(pET30fphnAlfA2f) or 154 BL21(DE3)(pVLT31phnAlfA2f) complemented with pEB431, carrying ferredoxin (phnA3) 155 and ferredoxin reductase (phnA4) genes from Sphingomonas sp. strain CHY-1 (Demaneche et 156 al. 2004), were grown overnight in $5 \mathrm{ml}$ LB medium with the suitable antibiotics. This culture 157 was used to inoculate $25 \mathrm{ml} \mathrm{LB}$ medium ( $0.1 \% \mathrm{vol} / \mathrm{vol})$, which was incubated at $37^{\circ} \mathrm{C}$ until an $158 \mathrm{OD}_{600}$ of 0.5 . IPTG was added to a final concentration of $0.5 \mathrm{mM}$. The cells were further 159 incubated overnight at $25^{\circ} \mathrm{C}$. For in vivo assays, cells were centrifuged, washed and 160 resuspended to an $\mathrm{OD}_{600}$ of approximately 2 in $\mathrm{M} 9$ medium (Sambrook et al. 1990) 161 containing $0.2 \%$ glucose. Cells (12 ml) overexpressing PhnA1fA2f, PhnA3 and PhnA4 were 162 incubated overnight at $25{ }^{\circ} \mathrm{C}$ with $2 \mathrm{ml}$ silicone oil containing $400 \mu \mathrm{M}$ of each tested 163 substrate. 
165 GC-MS analysis of PAH oxidation products. Water-soluble products resulting from PAH

166 oxidation were extracted from the aqueous phase of bacterial suspension by using columns

167 filled with reverse phase-bonded silica (Upti-clean C18U, $0.5 \mathrm{~g}$, Interchim, Montluçon,

168 France). Columns were washed with $10 \mathrm{ml}$ water then eluted with $1 \mathrm{ml}$ ethyl acetate. The

169 solvent was dried over sodium sulphate and evaporated under nitrogen gas. The dried extracts

170 were then dissolved in 100 or $200 \mu \mathrm{l}$ acetonitrile, before being derivatized with $\mathrm{N}, \mathrm{O}$ -

171 bis(trimethylsilyl)trifluoroacetamide containing trimethylchlorosilane (BSTFA) or $n$ -

172 butylboronate (NBB). In order to quantify the dihydrodiols formed upon incubation of

173 BL21(DE3)(pET30fphnA1fA2f) recombinant cells with PAHs, 2,3-dihydrobiphenyl (Sigma-

174 Aldrich, St. Louis, MO) was added to $0.1 \mu \mathrm{M}$ final concentration in the aqueous phase prior

175 to solid phase extraction, and was used as an internal standard. After derivatization and GC-

176 MS analysis, NBB dihydrodiol derivates were quantified on the basis of peak area using a

177 calibration curve generated by analysing known amounts of 3,4-phenanthrenedihydrodiol.

178 GC-MS analysis of trimethylsilyl derivatives was carried out as previously described

179 (Jouanneau et al. 2006). NBB derivatives were separated on MDN-12 capillary column (30 m,

$180 \quad 0.25 \mathrm{~mm}$ internal diameter; Supelco) using helium as carrier gas at $1 \mathrm{ml} / \mathrm{min}$. The oven

181 temperature was held at $75^{\circ} \mathrm{C}$ for $1 \mathrm{~min}$, then increased to $300^{\circ} \mathrm{C}$ at a rate of $14^{\circ} \mathrm{C} \mathrm{min}{ }^{-1}$, and

182 held at $300^{\circ} \mathrm{C}$ for $8 \mathrm{~min}$. The mass spectrometer was operated in the selected ion-monitoring

183 mode, selecting $\mathrm{m} / \mathrm{z}$, values corresponding to the expected masses $\left(\mathbf{M}^{+}\right)$of the dihydrodiol

184 derivatives.

185

186 DNA and protein sequence analysis. Sequence analysis was performed using the

187 DNASTAR software package (Lasergene Inc., Madison, WI). The BLAST search tool was 188 used for homology searches (Altschul et al. 1997). Multiple alignments were produced using 189 the DNASTAR software. 
191 Nucleotide sequence accession numbers. The nucleotide sequences described in this report 192 have been deposited in the Genbank database under accession number EU024111 and 193 EU024112 for the salicylate 1-hydroxylase and lower pathway enzymes and the terminal 194 dioxygenase, respectively. 


\section{RESULTS}

196 Cloning and sequence analysis of genes encoding a terminal dioxygenase.

197 Sphingomonas sp. strain LH128 has been studied for its ability to degrade three-ring 198 azaarenes in cometabolism with phenanthrene but no genetic analysis was undertaken (van 199 Herwijnen et al. 2004). In order to detect genes potentially involved in the initial attack of 200 PAHs, a PCR strategy was chosen. The genes involved in phenanthrene oxidation by strain 201 LH128 were expected to display some similarity with counterparts already described in other 202 phenanthrene-degrading Sphingomonas species. Based on sequence similarities between a 203 conserved catabolic gene cluster encoding genes of central metabolism from 204 Novosphingobium aromaticivorans strain F199, Sphingomonas sp. strain CHY-1, 205 Sphingobium yanoikuyae strain B1 and Sphingomonas sp. strain LH128 (GenBank accession 206 number EU024111), we hypothesized that the genes encoding the terminal component of the 207 initial dioxygenase from strain LH128 showed conserved sequences and could be amplified 208 by PCR using primers RHDA1f-F and RHDA2f-R. A fragment of 2048 bp was obtained with 209 genomic DNA from Sphingomonas sp. strain LH128 as template. The encoded proteins 210 (PhnA1fA2f) shared 99\%, 78\%, 78\% identity ( $\alpha$ subunit) and 98\%, 70\% and 63\% ( $\beta$ subunit) 211 with counterparts from Novosphingobium aromaticivorans F199, Sphingobium yanoikuyae

212 B1, and Sphingomonas sp. strain CHY-1 respectively. Since the counterparts of the 213 Sphingomonas sp. strain LH128 isolated genes have been shown to be involved in the initial 214 attack of their respective substrate, the genes were called phnAlfA2f (substrate phenanthrene, 215 see below). Here we present functional data regarding a ring hydroxylating dioxygenase 216 closely related to BphA1fA2f from strain F199 for which no functional data are available.

\section{Functional expression of PhnA1fA2f in E. coli.}

219 In order to investigate the substrate range of PhnA1fA2f, the corresponding genes were PCR220 amplified and cloned into the expression vector pET30f. The resulting construction was 
221 introduced into E. coli BL21(DE3) for SDS-PAGE analysis of IPTG-induced proteins. The 222 cells overproduced two polypeptides with the expected size of 50,000 Da and 20,000 Da (Fig. 223 1). However, the proteins were mainly insoluble (inclusion bodies) and recombinant cells did 224 not show detectable oxygenase activity. The phnAlfA2f sequence was therefore subcloned 225 behind the Ptac promoter into the broad host-range vector pVLT31 (de Lorenzo et al. 1993) 226 and introduced into E. coli BL21(DE3). When induced with IPTG, the recipient cells 227 produced appreciable levels of $50-\mathrm{kDa}$ and $20-\mathrm{kDa}$ polypeptides, which appeared to form a 228 soluble recombinant protein (Fig. 1). In order to provide the terminal oxygenase component 229 with an appropriate electron transport chain, plasmid pEB431, expressing phnA3 and phnA4 230 (Demaneche et al. 2004) was co-transformed into E. coli BL21(DE3). PhnA3 and PhnA4 231 formed with PhnA1fA2f a competent enzymatic complex in the E. coli host as proved by 232 indigo formation compared to cells lacking pEB431.

\section{Substrate range of PhnA1fA2f.}

235 The recombinant E. coli strain producing PhnA1f, PhnA2f, PhnA3 and PhnA4 was incubated 236 overnight separately with several representative PAHs, dibenzo- $p$-dioxin and PCBs. The 237 water-soluble products released into the culture medium were extracted and analysed by GC238 MS (Table 1) as described elsewhere (Krivobok et al. 2003). Since Sphingomonas sp. strain 239 LH128 is able to use fluorene, dibenzothiophene, and anthracene in cometabolic degradation 240 (Bastiaens et al. 2000) we tested whether PhnA1fA2f was responsible for the initial attack on 241 these compounds. The relative activity toward each PAH was calculated from the GC-MS 242 selected ion monitoring peak areas of the NBB derivatives compared to an internal standard 243 (2,3-dihydroxybiphenyl). Naphthalene was the preferred substrate (100\%), then phenanthrene 244 (43.3\%), biphenyl (31.8\%) and anthracene (28.7\%) were converted at significant but lower 245 rates to the corresponding dihydrodiols. Since naphthalene cannot support growth of strain 246 LH128, the genes were called $p h n A 1 f A 2 f$. Interestingly, PhnA1fA2f was also able to oxidize 
247 the heteroatomic analogues of fluorene i.e. dibenzofuran, dibenzothiophene and carbazole. 248 Strain LH128 is able to degrade fluorene in cometabolism with phenanthrene as the main 249 carbon source (Bastiaens et al. 2000). However, only traces of fluorenedihydrodiol were 250 detected after $n$-butylboronate (NBB) derivatization, a result that did not account for the 251 substantial cometabolic activity of strain LH128 towards fluorene. GC-MS analysis of TMS 252 derivatives of fluorene oxidation products allowed identification of a large peak of 253 monohydroxyfluorene (RT $16.262 \mathrm{~min}$ ) with significant fragment ions at m/z 254 (100), 239 254 (95), 165 (80), 152 (19), 73 (31). Moreover dihydroxyfluorene (RT: 17.577 min; 342 (36), 255327 (4), 253 (33), 223 (7), 73 (100) was detected, which most likely resulted from 256 hydroxylation of fluorene on two non-adjacent carbon atoms because it could not be detected 257 by NBB derivatization. Detection of monohydroxycarbazole (RT: $17.092 \mathrm{~min} ; \mathrm{m} / z 255$ (100), 258239 (57), 224 (47), 166 (11)) after BSTFA derivatization suggests that PhnA1fA2f transforms 259 carbazole to an unstable dihydrodiol by lateral dioxygenation. Fluoranthene was also probably 260 oxidized to an unstable dihydrodiol, which was further converted to 8-hydroxyfluoranthene, 261 since the TMS derivative had the same GC-MS characteristics as those reported for the 262 oxidation product of fluoranthene by the PhnI dioxygenase from strain CHY-1 (RT: 20.365 $263 \mathrm{~min} ; \mathrm{m} / z 290$ (100), 275 (55), 215 (15), 201 (19), 200 (18), 189 (30)) (Jouanneau et al. 2006). 264 Since PhnA1fA2f displayed a relatively high activity towards biphenyl (31.8\%), we tested 265 whether PhnA1fA2f could oxidize halogenated biphenyls. Monochlorinated biphenyls such as 266 2-chlorobiphenyl (relative activity $6.6 \%$ ) and 4-chlorobiphenyl $(6.1 \%)$ were oxidized to 267 corresponding dihydrodiols, but 2,3-dichlorobiphenyl was not. Moreover PhnA1fA2f was 268 able to perform lateral oxygenation of dibenzo-p-dioxin. Interestingly, the four-ring PAH 269 benz $[a]$ anthracene was transformed into two compounds with masses and retention times 270 consistent with those of two dihydrodiol isomers. These products most likely bear hydroxyls 271 in positions 1,2 and 10,11 since the homologous enzyme from strain CHY-1 preferentially 272 hydroxylated benz $[a]$ anthracene on these carbons (Jouanneau et al, 2006). Chrysene and 
273 pyrene were oxidized to cis-3,4-dihydroxy-3,4-dihydrochrysene and cis-4,5-dihydroxy-4,5274 dihydropyrene based on the retention times of the purified dihydrodiols obtained with Phn1 275 (Jouanneau et al. 2006) and Pdo1 (Krivobok et al. 2003), respectively. The 5-ring PAH 276 benz $[a]$ pyrene did not produce any detectable dihydrodiol under identical conditions. These 278 279 data demonstrate that the PhnA1fA2f terminal oxygenase from strain LH128 displays exceptionally broad substrate specificity towards a wide range of aromatic hydrocarbons.

\section{DISCUSSION}

280 Sphingomonads are known to degrade a large spectrum of pollutants, ranging from mono- and 281 polycyclic hydrocarbons (Pinyakong et al. 2000; Story et al. 2001) to naphthalene sulfonate 282 (Stolz 1999), dibenzo-p-dioxin (Armengaud et al. 1998; Hong et al. 2002), and methylated 283 PAHs (Dimitriou-Christidis et al. 2007; Zylstra and Kim 1997). Most known degradation 284 pathways of homocyclic PAHs start with the formation of a dihydroxy PAH by hydroxylation 285 of two adjacent carbon atoms. This step is catalysed by dioxygenase enzymes with relaxed 286 substrate specificity, which determines the substrate range of the organism. The compounds 287 are further degraded to a limited number of intermediates such as $o$-phthalic acid or salicylic 288 acid, and then via ortho or meta cleavage to tricarboxylic acid cycle intermediates. The genes 289 for aromatic hydrocarbon degradation by sphingomonads are quite different from those found 290 in other genera both in terms of nucleotide sequence and of gene order (Pinyakong et al. 291 2003a). This unique gene arrangement, which is remarkably conserved among strains of 292 various origins, contrasts with that found in other degraders, such as pseudomonads.

293 To date only a few sphingomonads' initial dioxygenases have been well characterized: 294 BphA1fA2f from strain B1 (Ni Chadhain et al. 2007) and PhnI (Jouanneau et al. 2006) from 295 strain CHY-1. BphA1fA2f from strain F199 has been identified but further investigation to 296 assess its catalytic abilities is missing. While the initial dioxygenases from strains LH128 and 297 CHY-1 are related (78 \% identity), strain CHY-1 is able to grow on chrysene as the sole 298 source of carbon (Willison 2004) while strain LH128 cannot use chrysene as a substrate. 
299 Likewise, the dioxygenases from strains CHY-1 and B1 show apparent differences of 300 substrate specificity despite sharing an almost identical structure (Demaneche et al. 2004; 301 Jouanneau et al. 2006; Ni Chadhain et al. 2007). These observations suggest that there exists a 302 pool of highly conserved multicomponent dioxygenases in sphingomonads, with subtle 303 structural variations that would appear to be responsible for differences in selectivity toward 304 PAHs (Fig. 2). Six homologues to both large and small substrate binding components of ring 305 hydroxylating dioxygenases were identified $\left(b p h A 1_{[\mathrm{a}-\mathrm{f}]}-b p h A 2_{[\mathrm{a}-\mathrm{f}]}\right)$ in Sphingomonas 306 yanoikuyae strain B1 (Zylstra and Kim 1997), Sphingomonas sp. strain P2 (Pinyakong et al. 307 2003b) and Novosphingobium aromaticivorans strain F199 (Romine et al. 1999). Since the 308 genes isolated from strain LH128 display high homologies to catabolic genes from these 309 species, one can expect to find the missing dioxygenase encoding genes in strain LH128 $310\left(\operatorname{bph} A 1_{[\mathrm{a}, \mathrm{b} . \mathrm{e}]}-\operatorname{bph} A 2_{[\mathrm{a}, \mathrm{b}, \mathrm{e}]}\right)$. Moreover, studies of Sphingomonas population structures of several 311 PAH-contaminated soils by PCR-DGGE revealed that soils with the highest phenanthrene 312 concentrations showed the lowest Sphingomonas diversity (Leys et al. 2004). This indicates 313 that Sphingomonas species share a set of dioxygenases that probably originated as 314 phenanthrene catabolic genes and then, by duplication, evolved to degrade different 315 substrates. For instance, the enzymes involved in the initial step of PAH degradation exhibit a 316 greater variety than those involved in the catabolism of central metabolites such as salicylate 317 (Table 2). The overall identities between salicylate 1-hydroxylases are higher than the 318 identities between the respective ring-hydroxylating dioxygenases of the different strains. 319 This clearly indicates that the enzymes involved in the upper PAH catabolic pathways have a 320 more relaxed substrate specificity then the enzymes involved in the lower pathway.

321 When overexpressed in E. coli BL21(DE3), PhnA1fA2f was found to be responsible for the 322 oxidation of low and high molecular weight PAHs, dibenzo- $p$-dioxin and monochlorinated 323 biphenyls but not 2,3-dichlorobiphenyl. Traces of carbazole dihydrodiol were detected after 324 NBB derivatization, but monohydroxycarbazole was abundant. Resnick et al. (1993) reported 
325 the formation of monohydroxycarbazole, possibly as a result of dehydration of unstable 326 dihydrodiols. Phenanthrene (43.3\%), biphenyl (31.8\%) and anthracene (28.7\%) were 327 transformed into high levels of the corresponding cis-dihydrodiols. Oxidation products of 328 benz[a]anthracene, chrysene and pyrene (Table 1) were also identified in contrast with 329 naphthalene dioxygenases whose selectivity is limited to only two and three ring PAHs 330 (Ferraro et al. 2004; Gakhar et al. 2005; Kauppi et al. 1998). The five ring PAH 331 benz[a]pyrene did not give any detectable products. This suggests that benz[a]pyrene 332 probably does not fit into the catalytic pocket of PhnA1fA2f.

333 The catalytic pocket of the ring-hydroxylating dioxygenase from Sphingomonas sp. strain 334 CHY-1 has been recently described on the basis of its crystal structure, and the amino acids 335 lining the catalytic pocket were identified (Jakoncic et al. 2007a; 2007b). These residues are 336 conserved in the enzymes from Sphingomonas sp. strain LH128, Novosphingobium 337 aromaticivorans strain F199 and, with only two substitutions, in Sphingobium yanoikuyae 338 strain B1 (Jakoncic et al. 2007a) (data not shown), suggesting that the topology of the 339 substrate binding pocket is almost identical. However, these structural resemblances do not 340 explain the differences in substrate specificity of the dioxygenases. The crystal structure of 341 the ring hydroxylating dioxygenase from strain $\mathrm{CHY}-1$ showed that the entrance of the 342 catalytic pocket is covered by two flexible loops L1 and L2, exposed to the solvent. These 343 loops are predicted to control the substrate's access to the catalytic pocket (Jakoncic et al. 344 2007b). Since the sequence of these loops is only partly conserved in the LH128 enzyme (83 $345 \%$ and $63 \%$ identities for L1 and L2, respectively), it seems plausible that these structural 346 differences may be responsible for the lower activity of the LH128 dioxygenase towards high 347 molecular weight PAHs and its inability to oxidize benz[a]pyrene. The effects on the catalytic 348 activity of residue substitutions in the active site have been well investigated in the case of 349 naphthalene dioxygenase and biphenyl dioxygenases (Parales 2003; Parales et al. 1999; $3502000 \mathrm{a} ; 2000 \mathrm{~b}$ ), but the effect of substitutions outside the catalytic pocket is less well 
351 documented (Furukawa et al. 2004; Zielinski et al. 2003; 2006). Our results indicate that

352 residues in the loops at the entrance of the catalytic pocket are potentially interesting targets

353 for mutagenesis as a means to better understand the structural determinants of selectivity.

354 In summary, we identified the genes encoding the dioxygenase responsible for the initial 355 attack on various PAHs by Sphingomonas sp. strain LH128 and expressed them in E. coli. 356 The dioxygenase PhnA1fA2f was closely related to BphA1fA2f from Novosphingobium 357 aromaticivorans strain F199 and, to a lower extent, to PhnI from Sphingomonas sp. strain 358 CHY-1 and BphA1fA2f Sphingobium yanoikuyae strain B1. Characterization of the activity 359 of the dioxygenase cloned in E. coli showed significant differences in catalytic activity 360 compared to the proteins PhnI from strain CHY-1 and BphA1fA2f from strain B1. This 361 indicates that small variations in amino acid sequence outside the catalytic pocket can have 362 substantial impact on dioxygenase selectivity. Significantly, PhnA1fA2f was able to oxidize 363 the four ring PAH benz[a]anthracene and yielded two dihydrodiols. 


\section{ACKNOWLEDGEMENTS}

365 L.S. gratefully acknowledges the Fund for the Promotion of Research in Industry and 366 Agriculture (F.R.I.A.), Belgium, for providing a doctoral fellowship. L.S. also wishes to thank 367 the members of the Unit of Physiological Biochemistry (FYSA), Catholic University of 368 Louvain, for their daily help and constructive remarks for many years. PH is a research 369 associate at the Belgian National Fund for Scientific Research (FNRS). 


\section{REFERENCES}

371 Altschul SF, Madden TL, Schaffer AA, Zhang J, Zhang Z, Miller W, Lipman DJ (1997)

372 Gapped BLAST and PSI-BLAST: a new generation of protein database search programs.

373 Nucleic Acids Res 25:3389-3402

374 Armengaud J, Happe B, Timmis KN (1998) Genetic analysis of dioxin dioxygenase of 375 Sphingomonas sp. strain RW1: catabolic genes dispersed on the genome. J Bacteriol 376 180:3954-3966

377 Bastiaens L, Springael D, Wattiau P, Harms H, deWachter R, Verachtert H, Diels L (2000) 378 Isolation of adherent polycyclic aromatic hydrocarbon (PAH)-degrading bacteria using PAH379 sorbing carriers. Appl Environ Microbiol 66:1834-1843

380 Bunz PV, Cook AM (1993) Dibenzofuran 4,4a-dioxygenase from Sphingomonas sp. strain 381 RW1: angular dioxygenation by a three-component enzyme system. J Bacteriol 175:6467$382 \quad 6475$

383 Butler CS, Mason JR (1997) Structure-function analysis of the bacterial aromatic ring384 hydroxylating dioxygenases. Adv Microb Physiol 38:47-84

385 Cai M, Xun L (2002) Organization and regulation of pentachlorophenol-degrading genes in 386 Sphingobium chlorophenolicum ATCC 39723. J Bacteriol 184:4672-4680

387 Cerniglia CE (1992) Biodegradation of poycyclic aromatic hydrocarbons. Biodegradation $388 \quad 3: 351-368$

389 de Lorenzo V, Eltis L, Kessler B, Timmis KN (1993) Analysis of Pseudomonas gene 390 products using lacl $^{\mathrm{q}} /$ Ptrp-lac plasmids and transposons that confer conditional phenotypes. 391 Gene 123:17-24

392 Demaneche S, Meyer C, Micoud J, Louwagie M, Willison JC, Jouanneau Y (2004) 393 Identification and functional analysis of two aromatic-ring-hydroxylating dioxygenases from 394 a Sphingomonas strain that degrades various polycyclic aromatic hydrocarbons. Appl Environ 395 Microbiol 70:6714-6725

396 Dimitriou-Christidis P, Autenrieth RL, McDonald TJ, Desai AM (2007) Measurement of 397 biodegradability parameters for single unsubstituted and methylated polycyclic aromatic 398 hydrocarbons in liquid bacterial suspensions. Biotechnol Bioeng 97:922-932 
399 Feng X, Ou LT, Ogram A (1997) Plasmid-mediated mineralization of carbofuran by 400 Sphingomonas sp. strain CF06. Appl Environ Microbiol 63:1332-1337

401 Ferraro DJ, Gakhar L, Ramaswamy S (2005) Rieske business: structure-function of rieske 402 non-heme oxygenases. Biochem Biophys Res Commun 338:175-190

403 Fortnagel P, Harms H, Wittich RM, Krohn S, Meyer H, Sinnwell V, Wilkes H, Francke W 404 (1990) Metabolism of dibenzofuran by Pseudomonas sp. strain HH69 and the mixed culture 405 HH27. Appl Environ Microbiol 56:1148-1156

406 Fujii K, Satomi M, Morita N, Motomura T, Tanaka T, Kikuchi S (2003) Novosphingobium 407 tardaugens sp. nov., an oestradiol-degrading bacterium isolated from activated sludge of a 408 sewage treatment plant in Tokyo. Int J Syst Evol Microbiol 53:47-52

409 Furukawa K, Suenaga H, Goto M (2004) Biphenyl dioxygenases: functional versatilities and 410 directed evolution. J Bacteriol 186:5189-5196

411 Gakhar L, Malik ZA, Allen CCR, Lipscomb DA, Larkin MJ, Ramaswamy S (2005) Structure 412 and increased thermostability of Rhodococcus sp. naphthalene 1,2-dioxygenase. J Bacteriol $413 \quad 197: 7222-7231$

414 Happe B, Eltis LD, Poth H, Hedderich R, Timmis KN (1993) Characterization of 2,2',3415 trihydroxybiphenyl dioxygenase, an extradiol dioxygenase from the dibenzofuran- and 416 dibenzo-p-dioxin-degrading bacterium Sphingomonas sp. strain RW1. J Bacteriol 175:7313$417 \quad 7320$

418 Hong HB, Chang YS, Nam IH, Fortnagel P, Schmidt S (2002) Biotransformation of 2,7419 dichloro- and 1,2,3,4-tetrachlorodibenzo-p-dioxin by Sphingomonas wittichii RW1. Appl 420 Environ Microbiol 68:2584-2588

421 Jakoncic J, Jouanneau Y, Meyer C, Stojanoff V (2007a) The catalytic pocket of the ring422 hydroxylating dioxygenase from Sphingomonas CHY-1. Biochem Biophys Res Commun $423 \quad 352: 861-866$

424 Jakoncic J, Jouanneau Y, Meyer C, Stojanoff V (2007b) The crystal structure of the ring425 hydroxylating dioxygenase from Sphingomonas CHY-1. FEBS J 274:2470-2481

426 Johannesen H, Sorensen SR, Aamand J (2003) Mineralization of soil-aged isoproturon and 427 isoproturon metabolites by Sphingomonas sp. strain SRS2. J Environ Qual 32:1250-1257 
428 Johnsen AR, Wick LY, Harms H (2005) Principles of microbial PAH-degradation in soil. 429 Environ Pollut 133:71-84

430 Jouanneau Y, Meyer C, Jakoncic J, Stojanoff V, Gaillard J (2006) Characterization of a 431 naphthalene dioxygenase endowed with an exceptionally broad substrate specificity toward 432 polycyclic aromatic hydrocarbons. Biochemistry 45:12380-12391

433 Kauppi B, Lee K, Carredano E, Parales RE, Gibson DT, Eklund H, Ramaswamy S (1998) 434 Structure of an aromatic-ring-hydroxylating dioxygenase-naphthalene 1,2-dioxygenase. 435 Structure 6:571-586

436 Kim E, Zylstra GJ (1999) Functional analysis of genes involved in biphenyl, naphthalene, 437 phenanthrene, and m-xylene degradation by Sphingomonas yanoikuyae B1. J Ind Microbiol 438 Biotechnol 23:294-302

439 Kim IS, Ryu JY, Hur HG, Gu MB, Kim SD, Shim JH (2004) Sphingomonas sp. strain SB5 440 degrades carbofuran to a new metabolite by hydrolysis at the furanyl ring. J Agric Food Chem $441 \quad 52: 2309-2314$

442 Kim S, Chun J, Bae K, Kim Y (2000) Polyphasic assignment of an aromatic-degrading 443 Pseudomonas sp., strain DJ77, in the genus Sphingomonas as Sphingomonas chungbukensis 444 sp. nov. Int J Syst Evol Microbiol 50:1641-1647

445 Krivobok S, Kuony S, Meyer C, Louwagie M, Willison JC, Jouanneau Y (2003) 446 Identification of pyrene-induced proteins in Mycobacterium sp. strain 6PY1: evidence for two 447 ring-hydroxylating dioxygenases. J Bacteriol 185:3828-3841

448 Leys NM, Ryngaert A, Bastiaens L, Verstraete W, Top EM, Springael D (2004) Occurrence 449 and phylogenetic diversity of Sphingomonas strains in soils contaminated with polycyclic 450 aromatic hydrocarbons. Appl Environ Microbiol 70:1944-1955

451 Mergeay M, Nies D, Schlegel HG, Gerits J, Charles P, Van Gijsegem F (1985) Alcaligenes 452 eutrophus $\mathrm{CH} 34$ is a facultative chemolithotroph with plasmid-bound resistance to heavy 453 metals. J Bacteriol 162:328-334

454 Ni Chadhain SM, Moritz EM, Kim E, Zylstra GJ (2007) Identification, cloning, and 455 characterization of a multicomponent biphenyl dioxygenase from Sphingobium yanoikuyae 456 strain B1. J Ind Microbiol Biotechnol 34:605-613 
457 Parales RE, Parales JV, Gibson DT (1999) Aspartate 205 in the catalytic domain of 458 naphthalene dioxygenase is essential for activity. J Bacteriol 181:1831-1837

459 Parales RE, Lee K, Resnick SM, Jiang H, Lessner DJ, Gibson DT (2000a) Substrate 460 specificity of naphthalene dioxygenase: effect of specific amino acids at the active site of the 461 enzyme. J Bacteriol 182:1641-1649

462 Parales RE, Resnick SM, Yu CL, Boyd DR, Sharma ND, Gibson DT (2000b) Regioselectivity 463 and enantioselectivity of naphthalene dioxygenase during arene cis-dihydroxylation: control 464 by phenylalanine 352 in the alpha subunit. J Bacteriol 182:5495-5504

465 Parales RE (2003) The role of active-site residues in naphthalene dioxygenase. J Ind 466 Microbiol Biotechnol 30:271-278

467 Peng X, Masai E, Kitayama H, Harada K, Katayama Y, Fukuda M (2002) Characterization of 468 the 5-carboxyvanillate decarboxylase gene and its role in lignin-related biphenyl catabolism 469 in Sphingomonas paucimobilis SYK-6. Appl Environ Microbiol 68:4407-4415

470 Pinyakong O, Habe H, Supaka N, Pinpanichkarn P, Juntongjin K, Yoshida T, Furihata K, 471 Nojiri H, Yamane H, Omori T (2000) Identification of novel metabolites in the degradation of 472 phenanthrene by Sphingomonas sp. strain P2. FEMS Microbiol Lett 191:115-121

473 Pinyakong O, Habe H, Omori $\mathrm{T}$ (2003a) The unique aromatic catabolic genes in 474 sphingomonads degrading polycyclic aromatic hydrocarbons (PAHs). J Gen Appl Microbiol $475 \quad 49: 1-19$

476 Pinyakong O, Habe H, Yoshida T, Nojiri H, Omori T (2003b) Identification of three novel 477 salicylate 1-hydroxylases involved in the phenanthrene degradation of Sphingobium sp. strain 478 P2. Biochem Biophys Res Commun 301:350-357

479 Resnick SM, Torok DS, Gibson DT (1993) Oxidation of carbazole to 3-hydroxycarbazole by 480 naphthalene 1,2-dioxygenase and biphenyl 2,3-dioxygenase. FEMS Microbiol Lett 113:297$481 \quad 302$

482 Romine MF, Stillwell LC, Wong KK, Thurston SJ, Sisk EC, Sensen C, Gaasterland T, J.K. F, 483 Saffer JD (1999) Complete sequence of a 184-kilobase catabolic plasmid from Sphingomonas 484 aromaticivorans F199. J Bacteriol 181:1585-1602 
485 Sambrook J, Fritsch EF, Maniatis T (1990) Molecular cloning: a laboratory manual. Cold 486 Spring Laboratory Harbor Press, Cold Spring Harbor, NY

487 Schuler L, Ni Chadhain SM, Jouanneau Y, Meyer C, Zylstra GL, Hols P, Agathos SN (2008) 488 Characterization of a novel angular dioxygenase from fluorene-degrading Sphingomonas sp. 489 strain LB126. Appl Environ Microbiol 74:1050-1057

490 Sorensen SR, Ronen Z, Aamand J (2001) Isolation from agricultural soil and characterization 491 of a Sphingomonas sp. able to mineralize the phenylurea herbicide isoproturon. Appl Environ 492 Microbiol 67:5403-5409

493 Stolz A (1999) Degradation of substituted naphthalenesulfonic acids by Sphingomonas 494 xenophaga BN6. J Ind Microbiol Biotechnol 23:391-399

495 Story SP, Parker SH, Hayasaka SS, Riley MB, Kline EL (2001) Convergent and divergent 496 points in catabolic pathways involved in utilization of fluoranthene, naphthalene, anthracene, 497 and phenanthrene by Sphingomonas paucimobilis var. EPA505. J Ind Microbiol Biotechnol $498 \quad 26: 369-382$

499 Thompson JD, Gibson TJ, Plewniak F, Jeanmougin F, Higgins DG (1997) The CLUSTAL_X 500 windows interface: flexible strategies for multiple sequence alignment aided by quality 501 analysis tools. Nucleic Acids Res 25:4876-4882

502 van Herwijnen R, de Graaf C, Govers HA, Parsons JR (2004) Estimation of kinetic parameter 503 for the biotransformation of three-ring azaarenes by the phenanthrene-degrading strain 504 Sphingomonas sp. LH128. Environ Toxicol Chem 23:331-338

505 Wackett LP (2002) Mechanism and application of Rieske non-heme iron dioxygenases. 506 Enzyme Microb Tech 31:577-587

507 Willison JC (2004) Isolation and characterization of a novel sphingomonad capable of growth 508 with chrysene as sole carbon and energy source. FEMS Microbiol Lett 241:143-150

509 Yrjala K, Paulin L, Kilpi S, Romantschuk M (1994) Cloning of cmpE, a plasmid-borne 510 catechol 2,3-dioxygenase-encoding gene from the aromatic- and chloroaromatic-degrading 511 Pseudomonas sp. HV3. Gene 138:119-121

512 Yu CL, Liu W, Ferraro DJ, Brown EN, Parales JV, Ramaswamy S, Zylstra GJ, Gibson DT, 513 Parales RE (2007) Purification, characterization, and crystallization of the components of a 
514 biphenyl dioxygenase system from Sphingobium yanoikuyae B1. J Ind Microbiol Biotechnol $515 \quad 34: 311-324$

516 Zielinski M, Kahl S, Hecht HJ, Hofer B (2003) Pinpointing biphenyl dioxygenase residues 517 that are crucial for substrate interaction. J Bacteriol 185:6976-6980

518 Zielinski M, Kahl S, Standfuss-Gabisch C, Camara B, Seeger M, Hofer B (2006) Generation 519 of novel-substrate-accepting biphenyl dioxygenases through segmental random mutagenesis 520 and identification of residues involved in enzyme specificity. Appl Environ Microbiol $521 \quad 72: 2191-2199$

522 Zylstra GJ, Kim E (1997) Aromatic hydrocarbon degradation by Sphingomonas yanoikuyae 523 B1. J Ind Microbiol Biotechnol 19:408-414 524 
Table 1. PAH selectivity of PhnA1A2f from Sphingomonas sp. LH128 as expressed in E. coli.

\begin{tabular}{|c|c|c|c|c|c|}
\hline Substrate $^{\mathrm{a}}$ & Products & $\begin{array}{c}\text { Molecular mass } \\
\text { of NBB derivative }\end{array}$ & $\begin{array}{l}\text { Retention } \\
\text { Time (min) }\end{array}$ & $\begin{array}{c}\text { Relative } \\
\text { activity }(\%)^{b}\end{array}$ & $\begin{array}{l}\mu \mathrm{M} \text { Diol/ } \\
\text { h mg Prot }^{c}\end{array}$ \\
\hline Biphenyl & cis-2,3-Dihydroxy-2,3-dihydrobiphenyl & 254 & 16.199 & 31.8 & 0.097 \\
\hline Naphthalene & cis-1,2-Dihydroxy-1,2-dihydronaphthalene & 228 & 14.479 & 100 & 0.306 \\
\hline Phenanthrene & cis-3,4-Dihydroxy-3,4-dihydrophenanthrene & 278 & 19.239 & 43.3 & 0.133 \\
\hline \multirow[t]{4}{*}{ Fluorene $^{d}$} & Fluorenedihydrodiol & 266 & 16.043 & 0.9 & 0.003 \\
\hline & Monohydroxyfluorene & & 15.836 & N.D. & N.D. \\
\hline & Monohydroxyfluorene & & 16.163 & N.D. & N.D. \\
\hline & Dihydroxyfluorene & & 17.577 & N.D. & N.D. \\
\hline Anthracene & cis-1,2-Dihydroxy-1,2-dihydroanthracene & 278 & 19.668 & 28.7 & 0.088 \\
\hline \multirow[t]{2}{*}{ Fluoranthene $^{d}$} & Fluoranthene-diol & 302 & 21.973 & 0.1 & 2.686E-04 \\
\hline & Monohydroxyfluoranthene & & 20.365 & N.D. & N.D. \\
\hline \multirow{2}{*}{ Benz $[a]$ anthracene } & cis-1,2-Benz $[a]$ anthracenedihydrodiol & 328 & 23.563 & 5.5 & 0.017 \\
\hline & cis-10,11-Benz $[a]$ anthracenedihydrodiol & 328 & 24.513 & 4.4 & 0.014 \\
\hline Pyrene & cis-4,5-Dihydroxy-4,5-dihydropyrene $e^{e}$ & 302 & 21.721 & Traces & Traces \\
\hline Chrysene & cis-3,4-Dihydroxy-3,4-dihydrochrysene $^{f}$ & 328 & 24.801 & 0.3 & $9.452 \mathrm{E}-04$ \\
\hline Benzo-p-dioxin & Benzo-p-dioxindihydrodiol & 284 & 17.936 & 2.4 & 0.007 \\
\hline Dibenzothiophene & Dibenzothiophenedihydrodiol & 284 & 18.949 & 12.6 & 0.039 \\
\hline \multirow[t]{2}{*}{ Dibenzofuran } & cis-1,2-Dihydroxy-1,2-dihydrodibenzofuran ${ }^{g}$ & 268 & 17.181 & 17.2 & 0.053 \\
\hline & Dibenzofurandihydrodiol & 268 & 17.611 & 5.3 & 0.016 \\
\hline
\end{tabular}




\section{Page 25 of 29}

Applied Microbiology and Biotechnology

1
2 532 total proteins. The values are averages of two separate determinations.

${ }^{c}$ Calculated from the GC-MS-selected ion monitoring peak areas of the NBB derivatives of the products formed after $24 \mathrm{~h}$ of incubation per mg of

${ }^{d}$ Dihydrodiols appear to be unstable and are spontaneously transformed to the corresponding monohydroxylated compounds by dehydration as detected after BSTFA derivatization. Therefore no relative activity is determined for these substrates (N.D.).

${ }^{e}$ Same retention time and mass spectrum as cis-4,5-dihydroxy-4,5-dihydropyrene produced by Pdo1 (Krivobok et al. 2003).

${ }^{f}$ Same retention time and mass spectrum as cis-3,4-dihydroxy-3,4-dihydrochrysene produced by Phn1 (Demaneche et al. 2004).

$g$ Same retention time and mass spectrum as oxidation products of dibenzofuran from Phn1 (Jouanneau et al. unpublished data). 
538 Table 2. Comparisons amongst salicylate 1-hydroxylase and the initial ring-hydroxylating 539 dioxygenase from Sphingomonas sp. strain P2, Novosphingobium aromaticivorans strain 540 F199, Sphingomonas sp. strain LH128, Sphingobium yanoikuyae strain B1 and Sphingomonas 541 sp. strain CHY1.

\begin{tabular}{|c|c|c|c|c|c|}
\hline $\begin{array}{l}\text { Ring-hydroxylating } \\
\text { dioxygenase }\end{array}$ & $\begin{array}{l}\mathrm{BphA1} \\
\mathrm{P}^{a}\end{array}$ & $\begin{array}{l}\text { BphA1f } \\
\text { F199 }\end{array}$ & $\begin{array}{l}\text { PhnA1f } \\
\text { LH128 }\end{array}$ & $\begin{array}{l}\text { BphA1f } \\
\mathrm{B} 1^{a}\end{array}$ & $\begin{array}{l}\text { PhnA1a } \\
\text { CHY-1 }\end{array}$ \\
\hline $\begin{array}{l}\text { BphA1f F199 } \\
\text { (YP_001165670) }\end{array}$ & & 100 & 99 & 78 & 78 \\
\hline $\begin{array}{l}\text { PhnA1f LH128 } \\
\text { (EU024112) }\end{array}$ & & & 100 & 77 & 77 \\
\hline $\begin{array}{l}\text { BphA1f B1 } \\
\text { (2GBW_A) }\end{array}$ & & & & 100 & 99 \\
\hline $\begin{array}{l}\text { PhnA1a CHY-1 } \\
\text { (2CKF_A) }\end{array}$ & & & & & 100 \\
\hline Salicylate 1-hydroxylase & $\begin{array}{l}\text { BphA1c } \\
\text { P2 }\end{array}$ & $\begin{array}{l}\text { BphA1c } \\
\text { F199 }\end{array}$ & $\begin{array}{l}\text { PhnA1c } \\
\text { LH128 }\end{array}$ & $\begin{array}{l}\text { BphA2c } \\
\text { B1 }\end{array}$ & $\begin{array}{l}\text { PhnA1b } \\
\text { CHY-1 }\end{array}$ \\
\hline $\begin{array}{l}\text { BphA1c P2 } \\
\text { (BAC65426) }\end{array}$ & 100 & 79 & 79 & 96 & 79 \\
\hline $\begin{array}{l}\text { BphA1c F199 } \\
\text { (NP_049213) }\end{array}$ & & 100 & 97 & 76 & 97 \\
\hline $\begin{array}{l}\text { PhnA1c LH128 } \\
\text { (EU024111) }\end{array}$ & & & 100 & 76 & 76 \\
\hline $\begin{array}{l}\text { BphA2c B1 } \\
\text { (ABM79781) }\end{array}$ & & & & 100 & 76 \\
\hline $\begin{array}{l}\text { PhnA1b CHY-1 } \\
\text { (CAG17582) }\end{array}$ & & & & & 100 \\
\hline
\end{tabular}

$542{ }^{a}$ Amino acid identity to their respective counterparts is shown. 


\section{FIGURE LEGENDS}

544

545 Figure 1. Detection of PhnA1fA2f overproduced in E. coli BL21(DE3). A: E. coli 546 BL21(DE3)(pET30fphnAlfA2f) overproduced high amounts of 50-kDa and 20-kDa that were 547 mainly insoluble. B: E. coli BL21(DE3) harbouring pVLT31phnAlfA2f produced soluble 548 proteins. However the $\beta$ subunit could not be detected by SDS-PAGE. E. coli BL21(DE3) 549 harbouring pET30f (A) or pVLT31 (B) lacking the phnAlfA2f insert were used as controls 550 (C). Protein extracts from 4 clones induced by IPTG are shown (lanes 1-4). Molecular mass 551 (kDa): M1: Prestained PAGE Ruler (Fermentas, St. Leon Rot, Germany), M2: Prestained 552 Protein Marker, Broad Range (New England Biolabs, Ipswich, MA). The arrows show the 553 PhnA1fA2f subunits.

554

555 Figure 2. [Modified and updated after Pinyakong et al. (2003a)]. Comparison of the conserved 556 catabolic operon from Novosphingobium aromaticivorans strain F199 (Romine et al. 1999), 557 Sphingobium sp. strain P2 (Pinyakong et al. 2003b), Sphingobium yanoikuyae strain B1 558 (Zylstra and Kim 1997; Ni Chadhain et al. 2007), Sphingomonas sp. strain CHY-1 559 (Demaneche et al. 2004), Sphingomonas sp. strain HV3 (Yrjala et al. 1994) and 560 Sphingomonas chungbukensis strain DJ77 (Kim et al. 2000). The protein sequence identities 561 to the counterparts from strain F199 are indicated. 
562 Fig. 1

563

564

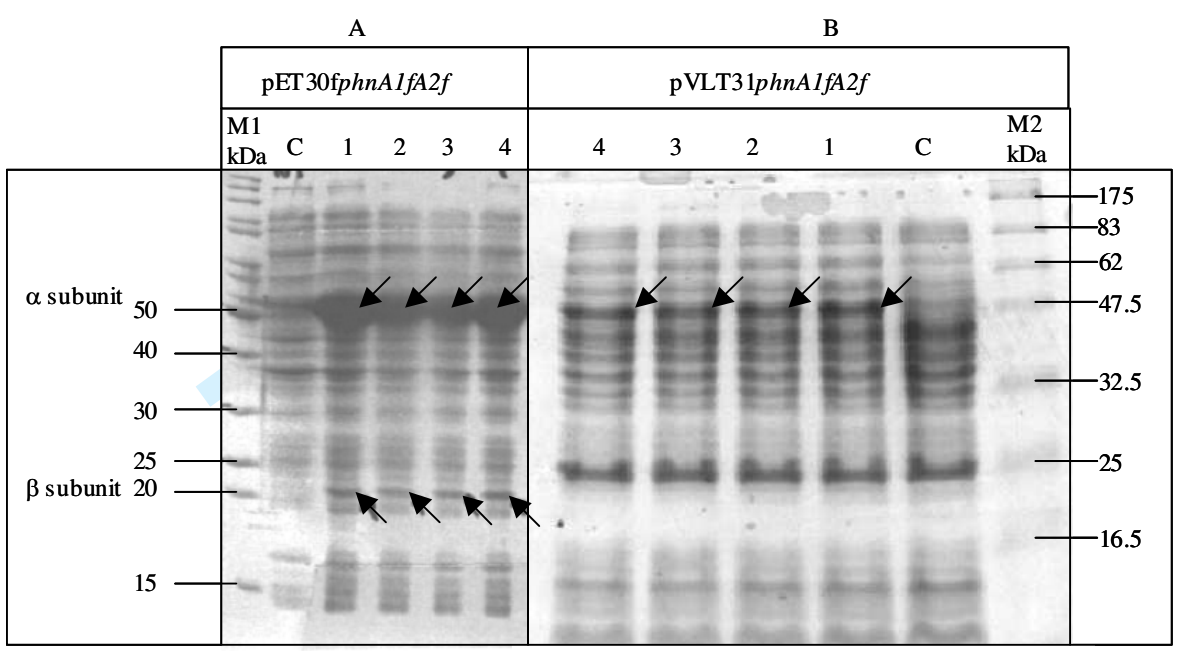

565

566 
《

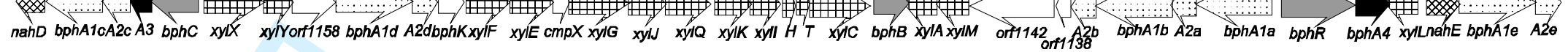

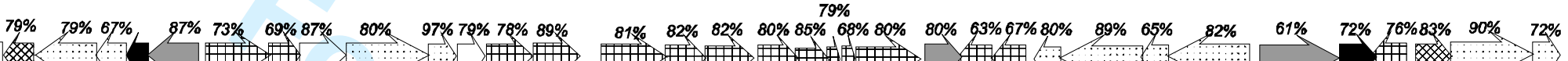
bphA1f A2f $-/ /-$ (1)

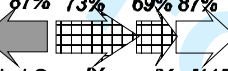
$97 \% 79 \% 78 \% 89 \%$

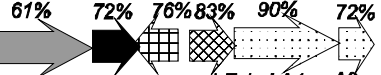

P2

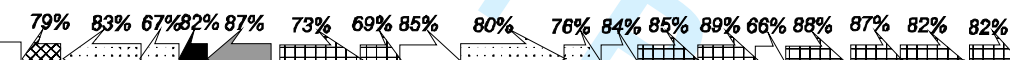

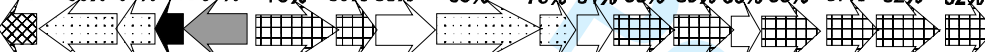
transposahD bphA1cA2c A3 bphC xylX xyIY orf9 bphA1d A2dbphKxylF xylE off15 xylG xylJ xyIQ xylK

$\mathrm{CHY}-1$

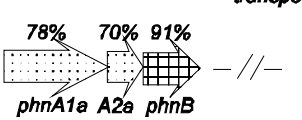
$98 \% \quad 98 \%$ $96 \% 96 \% 98 \% 97 \% 96 \%$

LH128: $98 \% \quad 98 \%$ phID PhnA1bA2b A3 phnC $79 \%$

X21 $-/ /-$

HV3

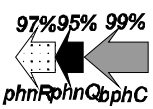

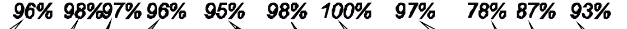
2..... \#

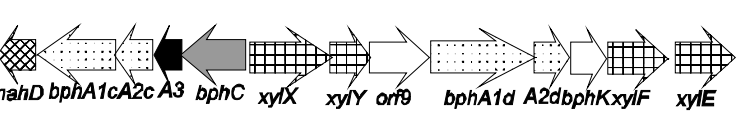

\section{$93 \% 95 \% 97 \% 96 \%$}

$$
\text { cmpF cmpEcmpX cmpC }
$$

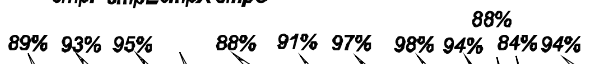

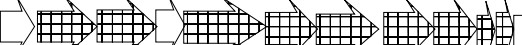

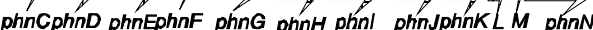

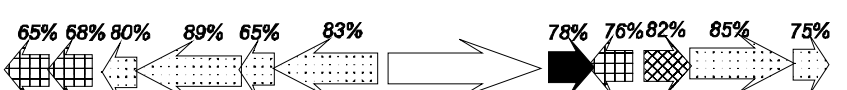
\#\# \# \# 